\title{
Durational Therapeutic Dose of Fansidar: A Functional Index in Its Antidiabetic Properties
}

\author{
E. 0. Jimmy \\ Department of Human Physiology, Faculty of Basic Medical Sciences, University of Uyo, Uyo, Nigeria \\ Email: medstedrecheo@yahoo.com
}

How to cite this paper: Jimmy, E.O. (2019) Durational Therapeutic Dose of Fansidar: A Functional Index in Its Antidiabetic Properties. Journal of Biosciences and Medicines, 7, 23-28. https://doi.org/10.4236/jbm.2019.71003

Received: June 15, 2018

Accepted: January 1, 2019

Published: January 4, 2019

Copyright $\odot 2019$ by author and Scientific Research Publishing Inc. This work is licensed under the Creative Commons Attribution International License (CC BY 4.0).

http://creativecommons.org/licenses/by/4.0/

\section{cc) (i) Open Access}

\begin{abstract}
Effects of fansidar in alloxan-induced diabetes were investigated in thirty (30) male and female albino rats for 28 days. The results showed a steady weekly decrease in blood glucose concentration in induced diabetic rats after fansidar treatment. In week 1, i.e. 7 days, there was significant difference in the blood glucose levels between the control and diabetic rats $(\mathrm{P}<0.05)$ i.e. high glucose concentration, same in week II i.e. 14 days. However, in day 21 i.e. week III there was a significant reduction in the blood glucose concentration compared with control $\mathrm{P}<0.05$. The same results were obtained in week IV i.e. in 28 days treatment. The result has shown that fansidar has antidiabetic potentials on long term durational administration.
\end{abstract}

\section{Keywords}

Durational Dosage, Diabetes, Antidiabetic Potentials

\section{Introduction}

Fansidar is a protective antimalaria drug which is acted by reciprocal potentiation of its two components: sulfadoxine $500 \mathrm{mg} \mathrm{N}-(5,6$ dimethoxyl-4-pyrimidinyl) and $25 \mathrm{mg}$ (2,4-diamino-5-(p-chlorophenyl-6-ethylpyrimidine) [1] .

Its therapeutic potential dwells in its sequential inhibition in the biosynthesis of tetrahydrofolic acid, an essential factor in the biosynthesis of neucleic acids necessary for formation of protozoal nucleic acid in the malarial parasites, while the sulfadoxine inhibits dihydrofolate reductase [2]. The administration of the drug for proper protective effect is weight dosage dependent. For more than 60 $\mathrm{kg}$ of weight it is 3 tablets taken once, $60 \mathrm{~kg}$ is 2 tablets, $5-10 \mathrm{~kg} ; 1 / 2$ tablet, 10 $20 \mathrm{~kg} ; 1$ tablet, $20-30 \mathrm{~kg} 1 / 2$ tablet, $30-45 \mathrm{~kg}-2$ tablets [3]. It is effective 
against chloroquine resistance strain of Plasmodium falciparum [4], but resistance against fansidar drug has also been observed [5]. The drug is very effective against the trophozoites and schizonts stages of parasite. Also it renders the gametocyte stage non-infective in the mosquitoes. The protective effect lasts for four weeks i.e. single dose of the drug.

The pharmacokinetics of fansidar for the two components shows peak plasma levels of sulfadoxine ranging from $51-76 \mathrm{mg} / \mathrm{L}$ in $4 \mathrm{hrs}$ with half life of 100 $250 \mathrm{hrs}$, whereas in pyrimethamine is $0.13-0.4 \mathrm{mg} / \mathrm{L}$ in $21-77 \mathrm{hrs}$ with half life of $54-148$ hrs. [6]

The volume of distribution for sulfadoxine and pyrimethamine is $0.14 \mathrm{~L} / \mathrm{kg}$ and $3 \mathrm{~L} / \mathrm{kg}$ respectively. Thus one tablet taken has a steady state plasma concentration of $98 \mathrm{mg} / \mathrm{L}$ for sulfadoxine for about several weeks and $0.15 \mathrm{mg} / \mathrm{L}$ for pyrime-thamine for about four weeks. The protein binding is about $90 \%$ for both sulfadoxine and pyrime-thamine and both crossed the placental barrier [7]. It has long elimination half life by the kidneys [8]. Adverse effects of skin reaction and gastrointestintestinal disorders do occur, [9]. Fansidar has antioxidative properties which is essential in parasite eradication, [10].

Alloxan is a urea derivative which causes selective necrosis of the pancreative islet of $\beta$ cells, it is used to produce experimental diabetes in animals e.g. rabbits, rats, mice, dogs, and the severity of the induced diabetes is dose dependent, [11]. The severe diabetes produced by alloxan results in blood sugar levels is equivalent to a total pancreatectomy. Alloxan is selectively toxic to insulin producing pancreatic beta cells because it preferentially accumulates in beta cells through uptake via, glucose (GLUT) glucose transporter [12]. The beta cells toxic action is as a result of the formation of reactive oxygen species (ROS) by alloxan with intracellular thiols and its reductive product; dialuric acid, [13]. Diabetes mellitus is a syndrome of chronic hypoglycemia due to relative insulin-deficiency and resistance. Insulin is produced by the pancreas which enhances the entry of glucose into the cells for the energy production, absent of insulin thus leads to increase presence of glucose in the blood [14]. More than 120 million people in the world are affected by this disease. Its complications involve macro-vascular disease, stroke, retinopathy and nephropathy. Symptoms include, polyuria, polydipsia, polyphagia. The normal glucose level is $70-120 \mathrm{mg} / \mathrm{dL}$, above this means diabetes. There are three main types of diabetes; type 1,2 and gestational diabetes. Type 1 is the insulin dependent diabetes mellitus (IDDM). It is an auto-immune disease which attacks and destroys insulin producing beta cells in the pancreas [15]. However, some persons may be resistant to the autoimmune attack. It is frequent in children, young adult and accounts for $90 \%-95 \%$ of the disease. It is also associated with old age, obesity, family history, physical inactivity, [16]. It is caused due to insulin resistance or reduced insulin sensitivity with reduced insulin secretion.

Gestational diabetes occurs only in pregnant women; due to hormones made during pregnancy that leads to the building up of glucose in the blood. It is often 
temporary and disappears after pregnancy. This type of diabetes carries long term risk as type 2 diabetes [17]. Such women are at risk of pregnancy complications during delivery. The defective responsiveness of the body tissue to insulin involves insulin receptor in the cell membrane [18]. Type 2 diabetes called non insulin dependent diabetes mellitus (NIDDM) results from the body's ineffective use of insulin. It accounts for the majority of people suffering from diabetes [19], it occurs in adult and children. There is impaired glucose tolerance (IGT) and impaired fasting glycemia (IFG) which are intermediate conditions between normal blood glucose levels in this type of diabetes, and the risk factors in this kind of transition. Symptoms are heart attacks and stroke and other symptoms are as in type I. Risk factors in developing diabetes include high blood pressure, high fat diet, high alcohol intake, obesity or over weight. Supportive therapies include anti diabetic drugs e.g. insulin, glibenclamide etc., self glucose monitoring, exercise, life style, modification in diets. The search for treatment of diabetes should be paramount to all scientists [20], due to the continuous upsurgent in the prevalent statistics of the disease and associated high mortality rate. The major aim of the study was to investigate the durational (i.e. 28 days) therapeutic effects of fansidar in diabetes treatment as different from other routine studies. And particularly the less side effects of the drug, its high availability and affordability than the real antidiabetic drugs.

\section{Material and Methods}

A total of 30 male and female albino rats were used, it was divided into three groups 10 in each group. Group 1 control with alloxan induced diabetes without treatment, group 2, normal control i.e. without diabetes and group 3 alloxan induced diabetes with fansidar treatment.

\subsection{Drugs Preparation and Administration}

1) Alloxan: This was prepared in $500 \mathrm{mg} / 10 \mathrm{ml}$ giving $50 \mathrm{mg} / \mathrm{ml}$. This was given orally using canula for three days $(72 \mathrm{hrs})$ for the induction of diabetes, $150 \mathrm{mg} / \mathrm{kg}-170 \mathrm{mg} / \mathrm{kg}$ could be used for stable diabetes in 35 days. The blood glucose levels were measured compared to control-using glucometer.

2) Fansidar: 3 tablets of $525 \mathrm{mg}$ were dissolved in $100 \mathrm{ml}$ of distilled water and $(0.4 \mathrm{mg} / \mathrm{ml}-0.8 \mathrm{mg} / \mathrm{ml})$ were administered orally using canula [21] by passing the esophagus and delivered into the stomach, [22]. Weekly observation, of the drug effects were made for 7, 14, 21 and 28 days.

\subsection{Blood Collection and Glucose Determination}

The rats were sacrificed by cardiac puncture using Chloroform anaesthesia after 7, 14, 21 and 28 days treatment. Five melilitre ( $5 \mathrm{ml}$ ), of blood was collected using syringe into EDTA bottles [23]. The glucose levels were determined using glucometer. A drop of blood was placed on the glucometer strip and results recorded in $\mathrm{g} / \mathrm{dL}$. 
Statistical analysis. Students t-test was used for analysis of data.

\section{Results}

The results showed that in day 7 treatment, rat with diabetes treated with fansidar had blood glucose level significantly higher than in rats without diabetes; $216.40 \pm 53.24,139.69 \pm 3.68(\mathrm{P}<0.05)$ and also higher than diabetic rats without treatment, $166.3 \pm 1.52$. $(\mathrm{P}<0.05)$, Table 1 , but on day 14 the glucose level was reduced in fansidar treated diabetic rats than those without treatment 135.5 $\pm 28.36,160 \pm 39.52$ but higher than in normal control, $118.7 \pm 4.99$. On day 21 there was also a great reduction in glucose levels in fansidar treated diabetic rats than those without treatment and normal control $91.84 \pm 5.27,150.0 \pm 8.7$, $131.33 \pm 17.09(\mathrm{P}<0.05)$. And on day 28 , the glucose level was also more drastically reduced in fansidar treated diabetic rats than in the diabetic rats without treatment and almost same in normal control, $81.92 \pm 14.08,154.8 \pm 17.27(\mathrm{P}<$ $0.05)$ and $81.1 \pm 13.57$ (Table 1).

\section{Discussion}

The investigation has revealed a steady weekly decrease in the blood glucose level of fansidar treated diabetic rats, study with non diabetic drug on glucose has same effect [24]. The non decrease in the 7 days treatment observation means that the fansidar concentration in the blood was not enough to effect a drastic reduction as in the diabetes control group without treatment. This indicates durational efficacy of this drug as shown in 14, 21 and 28 days. The implication is that for effective antidiabetic potentials of the drug, a longer administrative period is needed. The use of periodic timing in the study has beautifully revealed the hidden antidiabetic efficacy of the drug. This study is different from others by this pattern of treatment. Particularly, the pattern has conformed the long half life of the drug as it is still hoped that a longer period of observation perhaps up to three months would yield a more hypoglycemic state of the drug. Malaria investigation and observation is done far 30 days and repeat for relapse and recrudescence [25]. The study has predicted that malaria patients with diabetes will benefit from fansidar treatment. But malaria itself induces hypoglycemia as patients do not have appetite for food and this may affect negatively the antidiabetic effects of the fansidar treatment. The complication of diabetes mellitus and its associated morbidity is attributed to sustained hyperglycemia. With fansidar as potent glycemia index this will delay or prevent diabetes and enhances good

Table 1. Effect of fansidar on blood glucose levels in diabetic rats.

\begin{tabular}{ccc}
\hline Days of Treatment & Blood Glucose Levels mg/dl & P-Value \\
\hline 7 & $216.40 \pm 53.24$ & $\mathrm{P}<0.05$ \\
14 & $135.5 \pm 28.36$ & $\mathrm{P}<0.05$ \\
21 & $91.84 \pm 5.27$ & $\mathrm{P}<0.05$ \\
28 & $81.92 \pm 14.08$ & $\mathrm{P}<0.05$ \\
\hline
\end{tabular}


management of this disease. However, the mechanism of action of fansidar in reducing blood glucose is not known, perhaps is same with action of insulin in transporting glucose into the cells via GLUT4 transporter, [26].

\section{Recommendation}

Fansidar could be used in the treatment of diabetes based on longer duration of usage as observed in the study, but this awaits large epidemiological survey in human before such application. And in malaria patients there should be caution to avoid hypoglycemic situation, one of the complications of malaria disease but patients are free to continue with the prescribed antidiabetic drugs.

\section{Conflicts of Interest}

The author declares no conflicts of interest regarding the publication of this paper.

\section{References}

[1] Lazar, H.P., Hellgren, U.E. and Branden, J.A. (2000) Fansidar and Hepatic Granulomas. American Journal of Pharmacology, 102, 722.

[2] Schweitzer, B.I., Dicker, A.P. and Bertino, J.R. (1990) Dihydrofolate Reductase as a Therapeutic Target. FASEB Journal, 4, 244-252.

https://doi.org/10.1096/fasebj.4.8.2185970

[3] https://www.myvmc.com/drug/fansidar/

[4] Watkins, W.M. and Mosobo, M.A. (1993) Treatment of P. Falciparum Malaria with Pynmethamine-Sulphadoxine: Selective Pressure for Resistance. Journal of Tropical Medicine, 89, 75-78.

[5] Hurwtz, E.S., Johnson, D. and Campbell, C.C. (1981) Resistance of Plasmodium, falciparum Malaria to Sulfadonine-Pyrimethamine (Fansidar) in a Refugee Camp in That Land. Lancet, 16, 1068-1070. https://doi.org/10.1016/S0140-6736(81)92239-X

[6] Edstin, M.D. (1978) Pharmacokinetics of Sulphadoxine \& Pyrimethamine after Fansidar Administration. Chemotherapy, 33, 229-233.

https://doi.org/10.1159/000238499

[7] Moshad, D., Chilongola, J., Ndeserua, R., Nwingira, F. and Genton, B. (2014) Effectiveness of Intermittent Preventive Treatment with Sulphadoxine-Pyrimethamine during Pregnancy in Placental Malarial, Maternalanaemia and Birth Weight in Areas with High and Low Malaria Transmission Intensity in Tanzania. Tropical Medicine \& International Health, 19, 1048-1056. ttps://doi.org/10.1111/tmi.12349

[8] Umar, E.A., Adebayo, J.M. and Cletus, C.E. (2012) The Role of Biotransformation in Elimination of Toxic Waste. Journal of Clinical Biochemistry, 51, 207-208.

[9] Cunha, J.P. and Facoep, D.O. (2015) Side Effect of Fansidar Pyrimethamine/Sulphadoxine.

[10] Alexis, N., John, O. and Anne, M.M. (2013) Impact of Folate Supplementation on Efficacy of Sulfadoxine/Pyrimethamine in Preventing Malaria in Pregnancy; the Potentials of 5-Methyl Tetrahydrofolate. Journal of Antimicrobial Therapy, 69, 323-330.

[11] Huralikuppi, J.C. and Tatcho, M.A. (1998) Antidiabetic Effect of Nelumbo Nucifea Extract. Phytotherapy Research, 5, 217-223. https://doi.org/10.1002/ptr.2650050506 
[12] Ankur, R. and Shahjad, A. (2012) Alloxan Induced Diabetes: Mechanism and Effects. International Journal of Research in Pharmaceutical and Biomedical Sciences, 3, 819-823.

[13] Osasenaga, M.I., Abiola, M.A. and Oluseyi, A.A. (2017) Alloxan Induced Diabetes a Common Model for Evaluating the Glycemic Control Potential of Therapeutic Compounds and Plant Extracts in Experimental Studies. Medicina, 63, 365-374.

[14] Nelson, D.L. and Cox, M.M. (2000) Leninger; Principles of Biochemistry. 3rd Edition, Worth Publishers, Texas.

[15] https://beyondtype1.org/type1-diabetes-with-otherautoimmune-diseases

[16] Dhaliwal, R. and Weinstock, R.S. (2014) Management of Diabetes in Older Adult.

[17] Bellamy, L., Casas, J.-P., Hingorani, A.D. and Williams, D. (2009) Type 2 Diabetes Mellitus after Gestational Diabetes: A Systematic Review and Meta Analysis. The Lancet, 373, 1773-1779. https://doi.org/10.1016/S0140-6736(09)60731-5

[18] Pierre, D.M. (2016) The Insulin Receptor and Signal Transduction Network. Endotext (Internet). https://www.ncbi.nlm.nih.gov/books/NBK78978

[19] WHO (2016) Global Report on Diabetes Mellitus. World Health Organization, Geneva.

[20] Jimmy, E.O. and Udofia, A.J. (2014) Yoyo Bitters, a Potent Alternative Herbal Drug in the Treatment of Diabetes. International Journal of Innovative and Health Science, 2, 1-5.

[21] Bertram, G. (2004) Basic and Clinical Pharmacology. Sanfrancisco, New York, Chicago.

[22] Robert, G. (1979) Gastric Cytoprotective Property of Prostaglandins. Gastroenterology, 77, 762-769.

[23] Lewis, S.M., Bain, B.J. and Bates, I. (2007) Dacie and Lewis Practical Haematology. 10th Edition, Churchill Livingstone, London.

[24] Jimmy, E.O. and Okon, M.A. (2012) Periodic Validation of High Antidiabetic Potentials of Unripe Plantain in Comparison with Glibenclamide and Fansidar. American Journal of Pharmacology and Toxicology, 7, 15-18. https://doi.org/10.3844/ajptsp.2012.15.18

[25] Nicholas, J.W. (2011) Determinants of Relapse of Periodicity in Plasmodium vivax Malaria. Malaria Journal, 10, 297.

[26] Guyton, A.C. and Hall, J.E. (2006) Text Book of Medical Physiology. 11th Edition, Elsevier Saunders, Philadelphia, Pennsylvania. 